\title{
A Deep Learning Approach For Dental Implant Planning On Cone-Beam Computed Tomography Images
}

\author{
Sevda Kurt Bayrakdar \\ Eskisehir Osmangazi University \\ Kaan Orhan ( $\nabla$ call53@yahoo.com ) \\ Ankara University \\ Ibrahim Sevki Bayrakdar \\ Eskisehir Osmangazi University \\ Elif Bilgir \\ Eskisehir Osmangazi University \\ Matvey Ezhov \\ Diagnocat, Inc, San Francisco \\ Maxim Gusarev \\ Diagnocat, Inc, San Francisco \\ Eugene Shumilov \\ Diagnocat, Inc, San Francisco
}

\section{Research Article}

Keywords: Artificial intelligence, dental implant, implant planning, dentistry

Posted Date: March 13th, 2021

DOI: https://doi.org/10.21203/rs.3.rs-286578/v1

License: (c) (i) This work is licensed under a Creative Commons Attribution 4.0 International License. Read Full License 


\section{Abstract}

Background: The aim of this study was to evaluate the success of the artificial intelligence (Al) system in implant planning using three-dimensional cone-beam computed tomography (СВСT) images.

Methods: Seventy-five CBCT images were included in this study. In these images, bone height and thickness in 508 regions where implants were required were measured by a human observer with manual segmentation method using InvivoDental 6.0 (Anatomage Inc. San Jose, CA, USA). Also, canals/sinuses/fossae associated with alveolar bones and missing tooth regions were detected. After all of this evaluations were repeated using the deep convolutional neural network (Diagnocat, Inc.) The jaws were separated as mandible/maxilla and each jaw was grouped as anterior/premolar/molar teeth region. The data obtained from manual segmentation and Al methods were compared using Bland-Altman analysis and Wilcoxon signed rank test.

Results: In the bone height measurements, there were no statistically significant differences between Al and manual measurements in the premolar region of mandible and the premolar and molar regions of the maxilla $(p>0.05)$. In the bone thickness measurements, there were statistically significant differences between Al and manual measurements in all regions of maxilla and mandible $(p<0.001)$. Also, the percentage of right detection was $72.2 \%$ for canals, $66.4 \%$ for sinuses/fossae and $95.3 \%$ for missing tooth regions.

Conclusions: Development of Al systems and their using in future for implant planning will both facilitate the work of physicians and will be a support mechanism in implantology practice to physicians.

\section{Background}

Dental implants have been preferred by clinicians for many years in cases of the total, partial and single-tooth edentulism [1-3]. Detailed planning before the implant operation increases the success of the treatment due to the facility of placing in the correct position of the implant and eliminating the surgical risks [4-6]. For this purpose, in implant surgery, the various radiographic techniques are used to evaluate alveolar bone features (bone quality, thickness, and height) and anatomical variations in the operation area (such as nasal fossa, mandibular canal, mental foramen and sinuses) $[4,5,7]$.

Panoramic and intraoral radiographs are used still in dental implant practices to provide an overview of the jaws and to create a preliminary idea; but these radiographic techniques are insufficient for detailed implant planning $[4,8,9]$. Crosssectional tomograms such as computed tomography (CT) and cone-beam computed tomography (CBCT) which offer three-dimensional (3D) information to surgeons are currently used as an alternative to these conventional techniques [9]. СВСТ devices developed for dentomaxillofacial imaging, have more affordable prices and smaller device sizes than CT devices. It also offers high-quality images at a lower radiation dose and short scanning time $[4,9,10]$. It is known that СВСТ devices are very successful in determining the ideal implant sizes (ie, length and width) before the operation and in predicting the necessary extra surgical procedures (ie, guided tissue regeneration, splitting, sinus elevation) in case of insufficient bone in the operation site $[4,5,7,11]$. Nevertheless, the physician's knowledge, skills, and experience in the interpretation of CBCT images also play very great roles in performing detailed implant planning [12].

Artificial intelligence (Al) is a field of computer science aimed at performing various specific functions that require human intelligence. It imitates human intelligence and improves its these features acquired over time using the deep learning methods [13].

In radiological diagnostic clinics, using the Al has provided to emerge the computer-aided diagnosis (CAD) systems. Then the development of this system has gained momentum in many fields of medicine and its use also has become widespread in health sectors such as dentistry in recent years $[14,15]$. A deep convolutional neural network method $(\mathrm{DCNN})$ is a powerful deep learning application used on medical diagnostic images $[16,17]$. There are studies in the 
literature where this method, which also enables the processing of more complex images such as CBCT images, has used in various diagnostics in dentistry such as tooth numbering, periapical pathosis, and mandibular canal detection [18-21].

Many specialists and general practitioners have not received extensive training on radiographic image evaluation and not competent in detailed implant planning and interpretation of anatomical data [10,22]. This is a situation that makes challenges of dentistry practice and still awaits a solution. Using Al systems in radiographic interpretation provides many advantages to the physician and can contribute to solving this problem. Also, it may prevent wrong diagnosis and treatment planning (which may be due to work intensity, carelessness or inexperience), unnecessary loss of time/workload in dentistry [12].

To our best knowledge, there are no studies in the literature where Al systems are used in implant planning. The purpose of this study was to verify the diagnostic performance and assess the reliability of an artificial intelligence system based on the deep convolutional neural network method to implant planning in CBCT images.

\section{Methods}

\section{Patient selection and imaging}

A total of 75 patients' (cases with implant indication and recorded in 2019) CBCT images obtained from the CBCT archive of the Faculty of Dentistry of Eskişehir Osmangazi University were included in the study. Also, 508 measurements (in areas that have missing teeth and with implant indication) were performed from them. For the study procedures, the Noninterventional Clinical Research Ethics Committee Approval was received and principles of the Declaration of Helsinki were followed at each stage (decision date and number: 08.07.2019 and 2019 - 220). All images were acquired with the same CBCT scanner (Promax 3D Mid; Planmeca, Helsinki, Finland) and the same conditions. Diagnostic settings were as follows: $94 \mathrm{kVp}, 14 \mathrm{~mA}, 360^{\circ}$ rotation, $27 \mathrm{~s}$.

\section{Evaluation of tomography data}

All images were examined by an oromaxillofacial radiologist with at least 8 years of professional experience (i.Ş.B) by converting it to DICOM format. The jaws were separated as mandible/maxilla and each jaw was grouped as anterior / premolar/molar teeth region. Canine teeth and incisors were included in the anterior region. Canals/sinuses/fossae associated with alveolar bones were detected and missing teeth were recorded. In missing teeth areas, bone height and thickness were measured by manual segmentation methods using InvivoDental 6.0 (Anatomage Inc. San Jose, CA, USA). In other words, all evaluations were performed as in implant plannings; and limitations of anatomical structures were taken into consideration.

After manual evaluations, all files were randomly uploaded to the deep convolutional neural network (Diagnocat, Inc.) for determinations of canals/sinuses/fossae and calculation of bone length/width in missing teeth areas. The data obtained from manual segmentation and artificial intelligence (Al) methods were compared.

\section{Model Pipeline}

Diagnocat Al system prepares an implant planning report based on a pipeline of multiple fully convolutional networks and algorithmic slice extraction. Predictions crucial for implant planning include voxel-perfect segmentations of teeth, jaws, mandibular canals, maxillary sinuses, and missing teeth.

Missing teeth segmentation relies on both present teeth and jaws segmentations. A missing tooth mask is a virtual tooth mask that is extracted using neighboring teeth location, tilt, and placement according to a jaw. It allows to predict a mesiodistal angle of implant placement and provides a guide to a slicing algorithm.

Implant planning study includes a panoramic reformat of a specified jaw and a slice section with vestibulooral slice orientation. Teeth, jaws, and mandibular canal segmentations are used to build a panoramic ribbon of both a study image 
and a combined segmentation mask. All slices in a study are extracted from a region of interest (Rol) of a panoramic image ribbon with a user chosen step, $2 \mathrm{~mm}$ by default, and slice thickness, 1 voxel by default. Predicted target (missing) tooth and neighboring (potentially missing) teeth masks define a Rol and mesiodistal angle of slice extraction showing possible implant placement.

Every slice has two to three measurements providing information about possible implant size and direction. The first measurement shows a width of alveolar bone. The second measurement shows a distance from the first measurement line to the closest obstacle in implant direction which is either of mandibular canal, maxillary sinus, or a jaw bone edge. The third measurement is calculated only in mandible case and shows a vertical distance from an oral end of the first measurement line to a mandible bone edge.

\section{The architecture of the deep convolutional neural network}

Diagnocat models use rewritten and high-performing fully convolutional modified 3D U-Net architecture from [23] to obtain voxel-perfect segmentations of teeth and anatomy elements.

\section{Examiner consistency}

The measurements were performed by the same examiner. One hundred measurements were repeated 1 week after the first evaluation by the examiner. In this way, intra-examiner agreement and reliability were evaluated using intraclass correlation coefficients and intra-evaluator technical error measurement (TEM) calculations. The intraclass correlation coefficient ( $95 \%$ confidence interval) was 0.995 (0.992-0.997) for bone thickness; 0.996 (0.994-0.997) for bone height.

Also, relative TEM was 3.14 (acceptable) and reliability was $99.5 \%$ for bone thickness measurement, relative TEM was 2.37 (acceptable) and reliability was $99.6 \%$ for bone height measurements.

\section{Statistical Analyses}

Statistical analyses were performed with the SPSS 21.0 Package Data Program (SPSS 21.0 Software Package Program, Inc., Chicago, IL). Kolmogorov-Smirnov test was used when testing for normality. A comparison of measurements calculated by manual segmentation and artificial intelligence (Al) was made by Wilcoxon signed-rank test and BlandAltman analysis. A value of $\mathrm{P}<0.05$ was considered statistically.

\section{Results}

Correctness frequencies of canal/sinus/fossa/missing tooth detections of the Al system are listed in Table 1. The percentage of right detection was $72.2 \%$ for canals, $66.4 \%$ for sinuses/fossae. Also, it was seen that 484 ( $95.3 \%$ ) of 508 missing tooth regions were detected correctly and only 24 (4.7\%) was detected incorrectly. 
Table 1

False and right percentages of canal/sinus/fossa detections of the Al system.

\begin{tabular}{|c|c|c|c|c|c|c|c|c|}
\hline \multirow[t]{3}{*}{ REGIONS } & \multicolumn{4}{|c|}{ Canal/Sinus/Fossa Detection $(\%, n)$} & \multicolumn{4}{|c|}{ Missing tooth detection $(\%, \mathrm{n})$} \\
\hline & \multicolumn{2}{|c|}{$\begin{array}{l}\text { Canal Detection } \\
\text { (Mandibula) }\end{array}$} & \multicolumn{2}{|c|}{$\begin{array}{l}\text { Sinus/Fossa Detection } \\
\text { (Maxilla) }\end{array}$} & \multicolumn{2}{|c|}{ Mandibula } & \multicolumn{2}{|l|}{ Maxilla } \\
\hline & False & Right & False & Right & False & Right & False & Right \\
\hline Anterior & $\begin{array}{l}\% 83 \\
(n=44)\end{array}$ & $\begin{array}{l}\% 17 \\
(n=9)\end{array}$ & $\begin{array}{l}\% 91.8 \\
(n=56)\end{array}$ & $\begin{array}{l}\% 8.2 \\
(n=5)\end{array}$ & $\begin{array}{l}\% 9.4 \\
(n=5)\end{array}$ & $\begin{array}{l}\% 90.6 \\
(n=48)\end{array}$ & $\begin{array}{l}\% 8.2 \\
(n=5)\end{array}$ & $\begin{array}{l}\% 91.8 \\
(n=56)\end{array}$ \\
\hline Premolar & $\begin{array}{l}\% 29.5 \\
(n=18)\end{array}$ & $\begin{array}{l}\% 70.5 \\
(n=43)\end{array}$ & $\begin{array}{l}\% 27.7 \\
(n=28)\end{array}$ & $\begin{array}{l}\% 72.3 \\
(n=73)\end{array}$ & $\begin{array}{l}\% 3.3 \\
(n=2)\end{array}$ & $\begin{array}{l}\% 96.7 \\
(n=59)\end{array}$ & $\begin{array}{l}\% 5.9 \\
(n=6)\end{array}$ & $\begin{array}{l}\% 94.1 \\
(n=95)\end{array}$ \\
\hline Molar & $\begin{array}{l}\% 2.5 \\
(n=3)\end{array}$ & $\begin{array}{l}\% 97.5 \\
(n=117)\end{array}$ & $\begin{array}{l}\% 7.1 \\
(n=8)\end{array}$ & $\begin{array}{l}\% 92.9 \\
(n=104)\end{array}$ & $\begin{array}{l}\% 1.7 \\
(n=2)\end{array}$ & $\begin{array}{l}\% 98.3 \\
(n=118)\end{array}$ & $\begin{array}{l}\% 3.6 \\
(n=4)\end{array}$ & $\begin{array}{l}\% 96.4 \\
(n=108)\end{array}$ \\
\hline Total & $\begin{array}{l}\% 27.8 \\
(n=65)\end{array}$ & $\begin{array}{l}\% 72.2 \\
(n=169)\end{array}$ & $\begin{array}{l}\% 33.6 \\
(n=92)\end{array}$ & $\begin{array}{l}\% 66.4 \\
(n=182)\end{array}$ & $\begin{array}{l}\% 3.8 \\
(n=9)\end{array}$ & $\begin{array}{l}\% 96.2 \\
(n=225)\end{array}$ & $\begin{array}{l}\% 5.5 \\
(n=15)\end{array}$ & $\begin{array}{l}\% 94.5 \\
(n=259)\end{array}$ \\
\hline
\end{tabular}

The values of bone height and thickness measurements with the Al system and manual segmentation are shown in Table 2. The Al system was unable to perform 80 of bone height measurements (therefore, bone height measurements evaluated on 428 images) and 15 of bone thickness measurements (therefore, bone thickness measurements evaluated on 493 images).

Table 2

Bone height and thickness measurements with the Al system and manual segmentation

\begin{tabular}{|c|c|c|c|c|c|}
\hline \multirow[t]{4}{*}{ REGIONS } & & \multicolumn{4}{|l|}{ PARAMETERS } \\
\hline & & \multicolumn{2}{|c|}{$\begin{array}{l}\text { BONE HEIGHT MEASUREMENTS }(n= \\
\text { 428) } \#\end{array}$} & \multicolumn{2}{|c|}{$\begin{array}{l}\text { BONE THICKNESS MEASUREMENTS }(n= \\
493)^{\#}\end{array}$} \\
\hline & & Al & MANUEL & Al & MANUEL \\
\hline & & $\begin{array}{l}\text { MEDIAN (MIN- } \\
\text { MAX) }\end{array}$ & $\begin{array}{l}\text { MEDIAN (MIN- } \\
\text { MAX) }\end{array}$ & MEDIAN (MIN- MAX) & MEDIAN (MIN-MAX) \\
\hline \multirow[t]{3}{*}{ Mandibula } & Anterior & $19.2(3.1-31.6)$ & $12.8(5.7-19.1)$ & $5.7(1.2-11.8)$ & $4(2.1-10.8)$ \\
\hline & Premolar & $12(1.2-26.4)^{*}$ & $12(5-19.9) *$ & $6.1(2.4-11.7)$ & $4.6(2.5-11.1)$ \\
\hline & Molar & $10(1.2-19.2)$ & $11,7(2.6-20)$ & $7.7(4.5-13.8)$ & $5.2(3.3-12.5)$ \\
\hline \multirow[t]{3}{*}{ Maxilla } & Anterior & $24.3(3.9-27.3)$ & $13(3.6-16,6)$ & $6.5(3.9-31.1)$ & $4.4(2.1-18.9)$ \\
\hline & Premolar & $12.2(2.3-28.8) *$ & $12.1(2.4-22)^{*}$ & $7.2(2-34.4)$ & $4.9(0-11.1)$ \\
\hline & Molar & $6.9(0.5-26.3)^{*}$ & $7.6(0-17.6)^{*}$ & $9.5(1.6-29.5)$ & $5.6(0-15.2)$ \\
\hline \multicolumn{6}{|c|}{$\begin{array}{l}\text { *There were no differences between Al and manual measurements for each parameter }(P>0.05) \text {. Min, minimum; Max, } \\
\text { Maximum. }\end{array}$} \\
\hline
\end{tabular}


In the bone height measurements, there were no statistically significant differences between $\mathrm{Al}$ and manual measurements in the premolar region of mandible and the premolar and molar regions of the maxilla $(p>0.05)$. In the bone thickness measurements, there were statistically significant differences between Al and manual measurements in all regions of maxilla and mandible $(p<0.001)$. Bland Altman plots for measurements are shown in Figs. 2 and 3. Confidence interval for differences between the manuel and Al system are shown in Table 3.

Table 3

Confidence interval for differences of manuel and Al system

\begin{tabular}{|c|c|c|c|c|c|c|c|c|c|c|}
\hline \multirow[t]{3}{*}{ Parameters } & \multirow[t]{3}{*}{ Jaws } & \multirow[t]{3}{*}{ Regions } & \multicolumn{5}{|c|}{ Paired differences } & \multirow[t]{3}{*}{$\mathrm{t}$} & \multirow[t]{3}{*}{$\mathrm{df}$} & \multirow{3}{*}{$\begin{array}{l}\text { Sig (2- } \\
\text { tailed) }\end{array}$} \\
\hline & & & \multirow[t]{2}{*}{ Mean } & \multirow{2}{*}{$\begin{array}{l}\text { Standard } \\
\text { Deviation }\end{array}$} & \multirow{2}{*}{$\begin{array}{l}\text { Standard } \\
\text { Error } \\
\text { Mean }\end{array}$} & \multicolumn{2}{|c|}{$\begin{array}{l}\% 95 \mathrm{Cl} \text { of the } \\
\text { Difference }\end{array}$} & & & \\
\hline & & & & & & Lower & Upper & & & \\
\hline \multirow{6}{*}{$\begin{array}{l}\text { BONE } \\
\text { HEIGHT }\end{array}$} & \multirow[t]{3}{*}{ Mandibula } & Anterior & -5.79 & 6.11 & 0.89 & -7.58 & -3.99 & -6.49 & 46 & $\begin{array}{l}< \\
0.001\end{array}$ \\
\hline & & Premolar & -9.50 & 8.42 & 2.66 & -15.52 & -3.48 & -3.57 & 9 & 0,006 \\
\hline & & Molar & -1.02 & 4.99 & 0.66 & -2.35 & 0.30 & -1.55 & 56 & 0,126 \\
\hline & \multirow[t]{3}{*}{ Maxilla } & Anterior & -2.05 & 7.35 & 0.77 & -3.58 & -0.52 & -2.66 & 90 & 0,009 \\
\hline & & Premolar & 1.64 & 3.07 & 0.28 & 1.08 & 2.20 & 5.81 & 117 & $\begin{array}{l}< \\
0.001\end{array}$ \\
\hline & & Molar & -0.03 & 4.04 & 0.39 & -0.81 & 0.75 & -0.08 & 104 & 0,938 \\
\hline \multirow[t]{6}{*}{$\begin{array}{l}\text { BONE } \\
\text { THICKNESS }\end{array}$} & \multirow[t]{3}{*}{ Mandibula } & Anterior & -1.35 & 1.15 & 0.17 & -1.68 & -1.00 & -8.01 & 46 & $\begin{array}{l}< \\
0.001\end{array}$ \\
\hline & & Premolar & -4.04 & 7,62 & 0.97 & -5.99 & -2.09 & -4.14 & 60 & $\begin{array}{l}< \\
0.001\end{array}$ \\
\hline & & Molar & -1.46 & 1.46 & 0.19 & -1.85 & -1.07 & -7.53 & 56 & $\begin{array}{l}< \\
0.001\end{array}$ \\
\hline & \multirow[t]{3}{*}{ Maxilla } & Anterior & -5.28 & 8.42 & 0.84 & -6.95 & -3.60 & -6.26 & 99 & $<.001$ \\
\hline & & Premolar & -2.20 & 1.75 & 0.16 & -2.52 & -1.89 & -13.68 & 117 & $<.001$ \\
\hline & & Molar & -5.07 & 6.41 & 0.61 & -6.28 & -3.86 & -8.29 & 109 & $\begin{array}{l}< \\
0.001\end{array}$ \\
\hline
\end{tabular}

\section{Discussion}

In recent years, there has been a significant increase in the number of studies using Al for purposes such as disease detection and classification, organ and lesion segmentation in the medicine [24, 25]. With all these developments, the use of Al systems to interpret radiological images in dental radiology has also become widespread $[14,15,25]$. Using computer-aided systems in imaging techniques that require experience and expertise such as especially CT and CBCT will provide great convenience to physicians. But new academical studies are needed in this regard. In light of all this 
information, the present study aims the using DCNN during the planning of implants which is a popular treatment option in dentistry practice.

In the literature, there are studies reported the Al systems' using in a variety of dentistry situations such as detecting dental caries [26-29], root fractures [30-32], root morphologies [33], jaw pathologies [34], periodontal bone damages [35-38], periapical lesions [21] and also determinating teeth and their numbering [19, 39]. Analyzes of these studies, which are the pioneers of DCNN applications in dentistry, were made on a wide variety of radiographic imageries such as periapical, panoramic, bitewing cephalometric, CT and CBCT. Nevertheless, it is seen that the number of studies based on CT and CBCT is limited [25]. Johari et al. found that the probabilistic neural network (PNN) method was successful in determining vertical root fractures in their study on CBCT images [31]. Hiraiwa et al., also reported that Al showed acceptable results in determining the extra roots of teeth in $\mathrm{CBCT}$ [33]. Also, Orhan et al. reported in their study on periapical lesions in CBCT images that the volume measurements calculated with the convolutional neural network (CNN) method are compatible with manual measurements and this situation are promising for the future [21].

Treatment planning is one of the most important steps of workflow in both medicine and dentistry. For the success in the treatment, the correct diagnosis should be made first, then the ideal treatment planning should be created for the patient. Treatment planning is a detailed organizational process; it depends on many factors such as the physician's knowledge experience [40]. In recent years, artificial intelligence systems have been used to support decision making processes in the diagnosis and treatment planning of physicians. The neural network machine learning system was used in various treatment plans such as radiation therapy and orthognathic surgery and promising results were obtained [40-42]. As it is known, radiographic imaging plays an important role in the planning of dental implants. It is recommended to examine the operation site with 3-dimensional imaging systems before the operation and to make detailed planning by performing a series of measurements under conditions permitted by anatomic variations [5]. Formations such as mandibular canal, sinuses and nasal fossa evaluated in the current study are the main anatomic variations that shape the implant planning. Kwak et al. recently reported successful results in determining the mandibular canal by the CNN method in CBCT images and stated that this may be an opportunity for future dental planning [18]. Similarly, Fukuda et al. evaluated the relationship between the 3rd mandibular molar tooth and the mandibular canal in their study on 600 panoramic radiographs [43]. Jaskari et. al have used the CNN method for mandibular canal segmentation in al CBCT images. They stated that Al systems give sensitive and reliable results in canal determination and these systems may be an important role in future implant planning [44]. The results of our study were similar to these studies; and its success percentage was $97.9 \%$ in the mandibular canal detection.

In the present study, sinus/fossa and missing teeth detection analysis were also performed, and it was observed that Al systems showed a success of $66.4 \%$ and $95.3 \%$, respectively. It is seen that the number of studies regarding the detection of nasal fossa should be increased and the system should be improved. Because, as the success of the detection of anatomic structures in Al systems increases, the measurements made for implant planning will yield more successful results. To our best knowledge, there is no study in the literature for the determination of lost tooth/fossa and sinus, this is the first study on this subject. However, one study for determining sinus pathologies on panoramic images has been carried out and successful results of Al have been reported [45].

In this study, two separate measurements, bone thickness, and height were performed to evaluate the success of implant planning. The results of the study show that bone thickness measurements of Al should be improved using a deep learning system. We think this may be due to the measurement of the Al system with incorrect angles when evaluating bone thickness measurements. In the determination of nasal fossa in the maxilla and mandibular accessory canals in the mandibula, the system was not very sensitive; this situation caused some incompatibilities in the anterior region bone height measurements. 
While the determination of the mandibular canal was successful, it is found that the bone height could not be determined correctly in these regions. We think that this may be because the system did not take into account the implant diameter and thickness. This deficiency may cause the system to bypass the canal from the buccal/lingual of the canal during measurement. As a result, the Al system can report measurements in this region higher than they should.

However, it is seen that the results of the Al system consistent with the manual measurements in the maxilla molar/premolar region, as well as in the mandible premolar region; these results offer hope for the usability of the system in implant planning.

\section{Conclusion}

Consequently, using these systems in implant planning will both facilitate the work of physicians and will be a support mechanism in implantology practice. The success of the present study in the detection of sinus / mandibular canal and missing teeth and the measurements it offers in implant planning reinforces this possibility. There is a need for more extensive studies in which environmental anatomical formations are evaluated by Al for the development of CNN systems in implant planning.

\section{List Of Abbreviations}

Al: artificial intelligence; CBCT: cone-beam computed tomography; CT: computed tomography; 3D: three-dimensional; CAD: computer-aided diagnosis; DCNN: deep convolutional neural network; TEM: technical error measurement; PNN: probabilistic neural network; CNN: convolutional neural network

\section{Declarations}

\section{Ethics approval and consent to participate}

The research protocol was approved by the Eskisehir Osmangazi University Ethics Committee. All participants gave informed consent.

\section{Consent for publication}

Not applicable

\section{Availability of data and materials}

Not applicable

\section{Competing interests}

The authors declare that there is no conflict of interest

\section{Funding}

This research received no specific grant from any funding agency in the public, commercial, or not-for- profit sectors.

\section{Authors' contributions}

SKB Conceptualization, Writing of the original draft, KO Project administration, Review, and editing, ISB Investigation, Writing of the original draft, EB Investigation, Writing of the original draft, ME Conceptualization, Methodology, MG 
Conceptualization, Methodology, ES Conceptualization, Methodology. All authors read and approved the final version of the manuscript.

\section{Acknowledgements}

Not applicable

\section{References}

[1] Gaviria L, Salcido JP, Guda T, Ong JL. Current trends in dental implants. Journal of the Korean Association of Oral and Maxillofacial Surgeons 2014;40:50-60.

[2] Lindh T, Gunne J, Tillberg A, Molin M. A meta-analysis of implants in partial edentulism. Clinical oral implants research 1998;9:80-90.

[3] Albrektsson T, Wennerberg A. The impact of oral implants-past and future, 1966-2042. J Can Dent Assoc 2005;71:327.

[4] Correa LR, Spin-Neto R, Stavropoulos A, Schropp L, da Silveira HED, Wenzel A. Planning of dental implant size with digital panoramic radiographs, CBCT-generated panoramic images, and CBCT cross-sectional images. Clinical oral implants research 2014;25:690-5.

[5] Worthington P, Rubenstein J, Hatcher DC. The role of cone-beam computed tomography in the planning and placement of implants. The Journal of the American Dental Association 2010;141:19S-24S.

[6] Gaêta-Araujo H, Oliveira-Santos N, Mancini AXM, Oliveira ML, Oliveira-Santos C. Retrospective assessment of dental implant-related perforations of relevant anatomical structures and inadequate spacing between implants/teeth using conebeam computed tomography. Clinical oral investigations 2020:1-8.

[7] Sießegger M, Schneider BT, Mischkowski RA, Lazar F, Krug B, Klesper B, et al. Use of an image-guided navigation system in dental implant surgery in anatomically complex operation sites. Journal of Cranio-Maxillofacial Surgery 2001;29:276-81.

[8] Angelopoulos C, Thomas S, Hechler S, Parissis N, Hlavacek M. Comparison between digital panoramic radiography and cone-beam computed tomography for the identification of the mandibular canal as part of presurgical dental implant assessment. Journal of Oral and Maxillofacial Surgery 2008;66:2130-5.

[9] Suomalainen A, Vehmas T, Kortesniemi M, Robinson S, Peltola J. Accuracy of linear measurements using dental cone beam and conventional multislice computed tomography. Dentomaxillofacial Radiology 2008;37:10-7.

[10] Scarfe WC, Farman AG. What is cone-beam CT and how does it work? Dental Clinics of North America 2008;52:70730.

[11] Ekestubbe A, Gröndahl K, Gröndahl H. The use of tomography for dental implant planning. Dentomaxillofacial Radiology 1997;26:206-13.

[12] Zakirov A, Ezhov M, Gusarev M, Alexandrovsky V, Shumilov E. Dental pathology detection in 3D cone-beam CT. arXiv preprint arXiv:181010309 2018.

[13] Chartrand G, Cheng PM, Vorontsov E, Drozdzal M, Turcotte S, Pal CJ, et al. Deep learning: a primer for radiologists. Radiographics 2017;37:2113-31. 
[14] Sen D, Chakrabarti R, Chatterjee S, Grewal D, Manrai K. Artificial intelligence and the radiologist: the future in the Armed Forces Medical Services. BMJ Military Health 2019.

[15] Raja'a M, Farid F. Computer-based technologies in dentistry: types and applications. Journal of dentistry (Tehran, Iran) 2016;13:215.

[16] Han X. MR-based synthetic CT generation using a deep convolutional neural network method. Medical physics 2017;44:1408-19.

[17] Miki Y, Muramatsu C, Hayashi T, Zhou X, Hara T, Katsumata A, et al. Classification of teeth in cone-beam CT using deep convolutional neural network. Computers in biology and medicine 2017;80:24-9.

[18] Kwak GH, Kwak E-J, Song JM, Park HR, Jung Y-H, Cho B-H, et al. Automatic mandibular canal detection using a deep convolutional neural network. Scientific Reports 2020;10:1-8.

[19] Tuzoff DV, Tuzova LN, Bornstein MM, Krasnov AS, Kharchenko MA, Nikolenko SI, et al. Tooth detection and numbering in panoramic radiographs using convolutional neural networks. Dentomaxillofacial Radiology 2019;48:20180051.

[20] Muramatsu C, Kutsuna S, Takahashi R, Hayashi T, Nishiyama W, Ariji Y, et al. Tooth numbering in cone-beam CT using a relation network for automatic filing of dentition charts. Medical Imaging 2020: Imaging Informatics for Healthcare, Research, and Applications: International Society for Optics and Photonics; 2020. p. 113180L.

[21] Orhan K, Bayrakdar I, Ezhov M, Kravtsov A, Özyürek T. Evaluation of artificial intelligence for detecting periapical pathosis on cone-beam computed tomography scans. International Endodontic Journal 2020;53:680-9.

[22] Iannucci J, Howerton LJ. Dental Radiography-E-Book: Principles and Techniques: Elsevier Health Sciences; 2016.

[23] Isensee F, Kickingereder P, Wick W, Bendszus M, Maier-Hein KH. Brain tumor segmentation and radiomics survival prediction: Contribution to the brats 2017 challenge. International MICCAI Brainlesion Workshop: Springer; 2017. p. 287-97.

[24] Lee H, Tajmir S, Lee J, Zissen M, Yeshiwas BA, Alkasab TK, et al. Fully automated deep learning system for bone age assessment. Journal of digital imaging 2017;30:427-41.

[25] Schwendicke F, Golla T, Dreher M, Krois J. Convolutional neural networks for dental image diagnostics: A scoping review. Journal of Dentistry 2019;91:103226.

[26] Devito KL, de Souza Barbosa F, Felippe Filho WN. An artificial multilayer perceptron neural network for diagnosis of proximal dental caries. Oral Surgery, Oral Medicine, Oral Pathology, Oral Radiology, and Endodontology 2008;106:879-84.

[27] Valizadeh S, Goodini M, Ehsani S, Mohseni H, Azimi F, Bakhshandeh H. Designing of a computer software for detection of approximal caries in posterior teeth. Iranian Journal of Radiology 2015;12.

[28] Lee J-H, Kim D-H, Jeong S-N, Choi S-H. Detection and diagnosis of dental caries using a deep learning-based convolutional neural network algorithm. Journal of dentistry 2018;77:106-11.

[29] Moutselos K, Berdouses E, Oulis C, Maglogiannis I. Recognizing Occlusal Caries in Dental Intraoral Images Using Deep Learning. 2019 41st Annual International Conference of the IEEE Engineering in Medicine and Biology Society (EMBC): IEEE; 2019. p. 1617-20.

[30] Fukuda M, Inamoto K, Shibata N, Ariji Y, Yanashita Y, Kutsuna S, et al. Evaluation of an artificial intelligence system for detecting vertical root fracture on panoramic radiography. Oral Radiology 2019:1-7. 
[31] Johari M, Esmaeili F, Andalib A, Garjani S, Saberkari H. Detection of vertical root fractures in intact and endodontically treated premolar teeth by designing a probabilistic neural network: an ex vivo study. Dentomaxillofacial Radiology 2017;46:20160107.

[32] Kositbowornchai S, Plermkamon S, Tangkosol T. Performance of an artificial neural network for vertical root fracture detection: an ex vivo study. Dental traumatology 2013;29:151-5.

[33] Hiraiwa T, Ariji Y, Fukuda M, Kise Y, Nakata K, Katsumata A, et al. A deep-learning artificial intelligence system for assessment of root morphology of the mandibular first molar on panoramic radiography. Dentomaxillofacial Radiology 2019;48:20180218.

[34] Poedjiastoeti W, Suebnukarn S. Application of convolutional neural network in the diagnosis of jaw tumors. Healthcare informatics research 2018;24:236-41.

[35] Lee J-H, Kim D-h, Jeong S-N, Choi S-H. Diagnosis and prediction of periodontally compromised teeth using a deep learning-based convolutional neural network algorithm. Journal of periodontal \& implant science 2018;48:114-23.

[36] Krois J, Ekert T, Meinhold L, Golla T, Kharbot B, Wittemeier A, et al. Deep learning for the radiographic detection of periodontal bone loss. Scientific reports 2019;9:1-6.

[37] Chang H-J, Lee S-J, Yong T-H, Shin N-Y, Jang B-G, Kim J-E, et al. Deep Learning Hybrid Method to Automatically Diagnose Periodontal Bone Loss and Stage Periodontitis. Scientific Reports 2020;10:1-8.

[38] Kim J, Lee H-S, Song I-S, Jung K-H. DeNTNet: Deep Neural Transfer Network for the detection of periodontal bone loss using panoramic dental radiographs. Scientific reports 2019;9:1-9.

[39] Chen H, Zhang K, Lyu P, Li H, Zhang L, Wu J, et al. A deep learning approach to automatic teeth detection and numbering based on object detection in dental periapical films. Scientific reports 2019;9:1-11.

[40] Choi H-I, Jung S-K, Baek S-H, Lim WH, Ahn S-J, Yang I-H, et al. Artificial intelligent model with neural network machine learning for the diagnosis of orthognathic surgery. Journal of Craniofacial Surgery 2019;30:1986-9.

[41] Wang C, Zhu X, Hong JC, Zheng D. Artificial intelligence in radiotherapy treatment planning: present and future. Technology in cancer research \& treatment 2019;18:1533033819873922.

[42] Lee K-S, Ryu J-J, Jang HS, Lee D-Y, Jung S-K. Deep Convolutional Neural Networks Based Analysis of Cephalometric Radiographs for Differential Diagnosis of Orthognathic Surgery Indications. Applied Sciences 2020;10:2124.

[43] Fukuda M, Ariji Y, Kise Y, Nozawa M, Kuwada C, Funakoshi T, et al. Comparison of 3 deep learning neural networks for classifying the relationship between the mandibular third molar and the mandibular canal on panoramic radiographs. Oral Surgery, Oral Medicine, Oral Pathology and Oral Radiology 2020.

[44] Jaskari J, Sahlsten J, Järnstedt J, Mehtonen H, Karhu K, Sundqvist O, et al. Deep Learning Method for Mandibular Canal Segmentation in Dental Cone Beam Computed Tomography Volumes. Scientific reports 2020;10:1-8.

[45] Kim Y, Lee KJ, Sunwoo L, Choi D, Nam C-M, Cho J, et al. Deep learning in diagnosis of maxillary sinusitis using conventional radiography. Investigative radiology 2019;54:7-15.

\section{Figures}



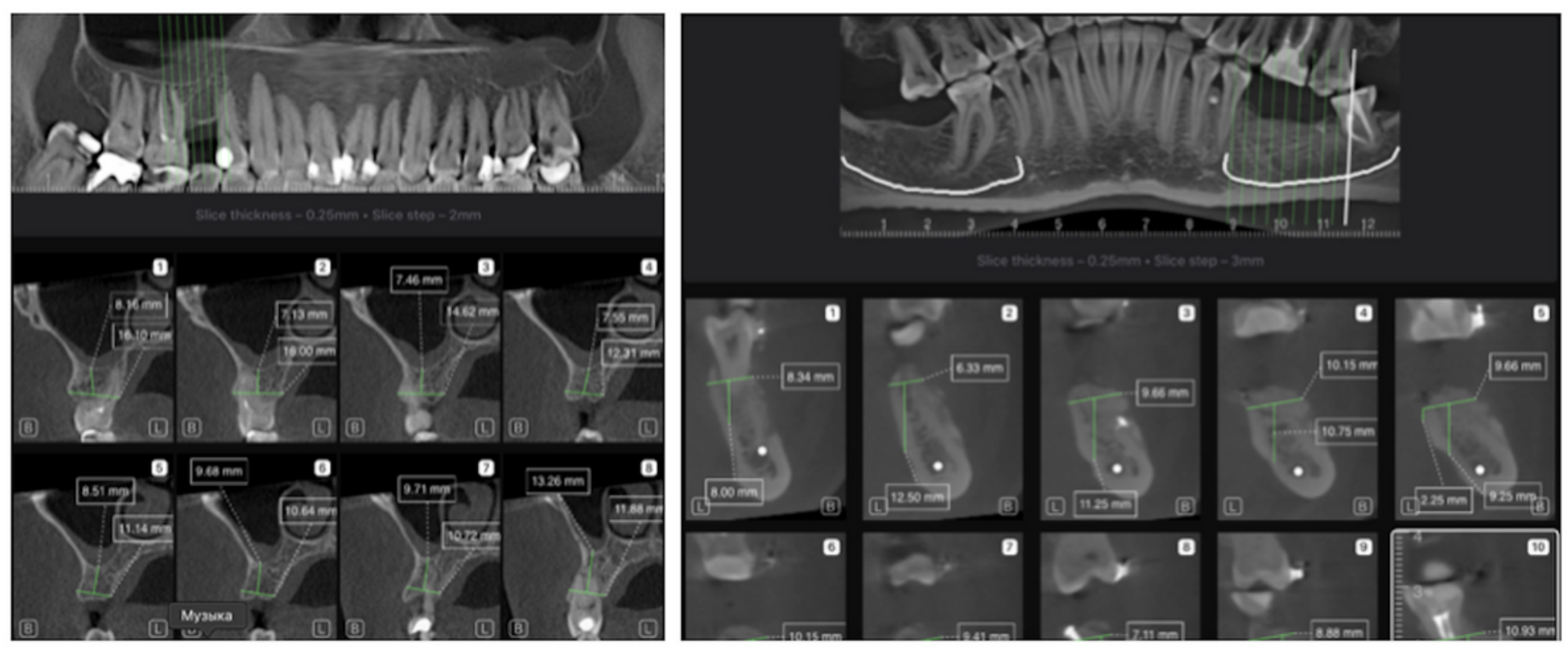

\section{Figure 1}

Implant planning report which was created otomatically for maxilla and mandibula case using the Al.
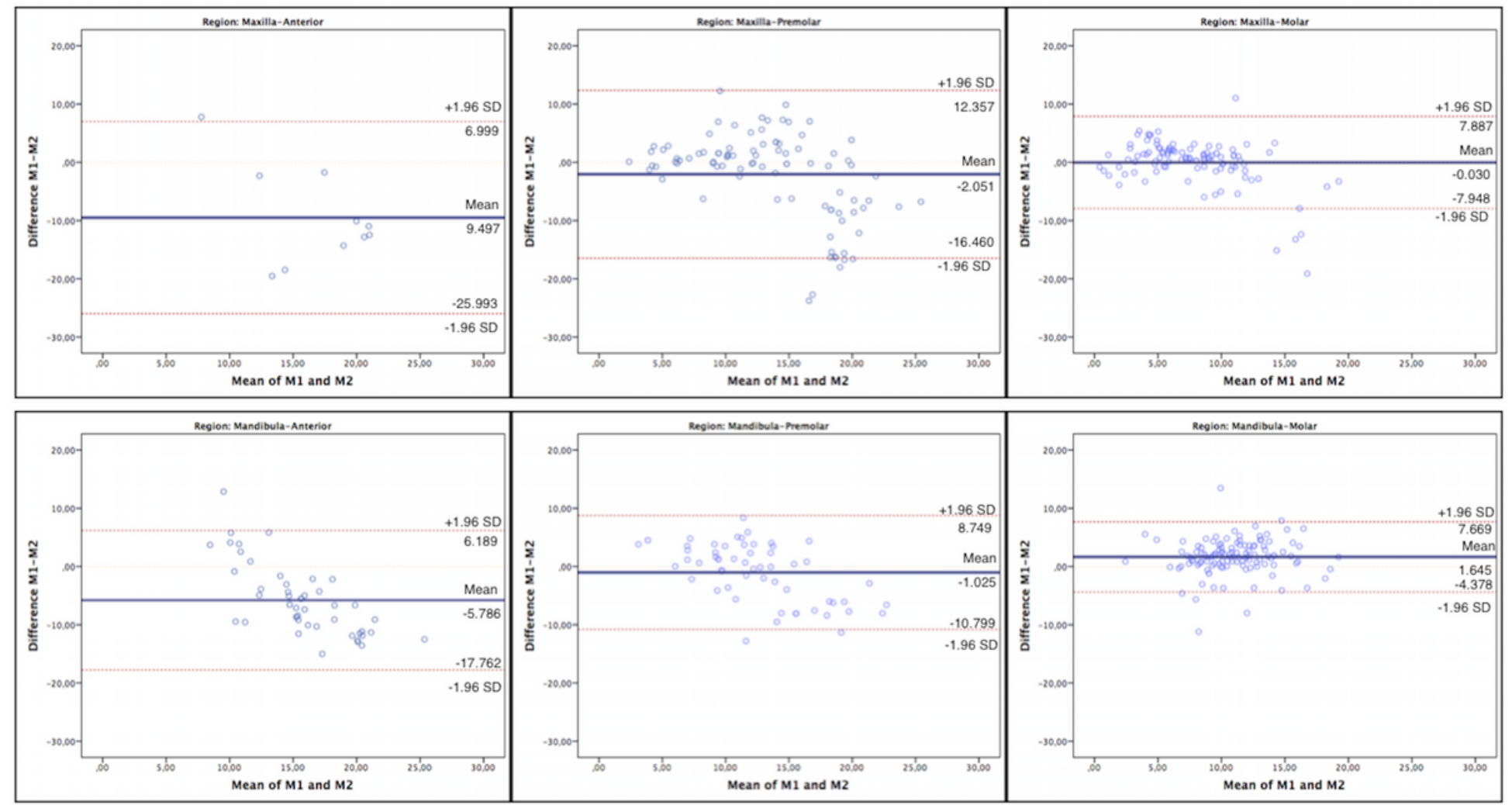

\section{Figure 2}

Bland Altman plots for bone height. M1, Manuel measurements; M2, Al measurements. 


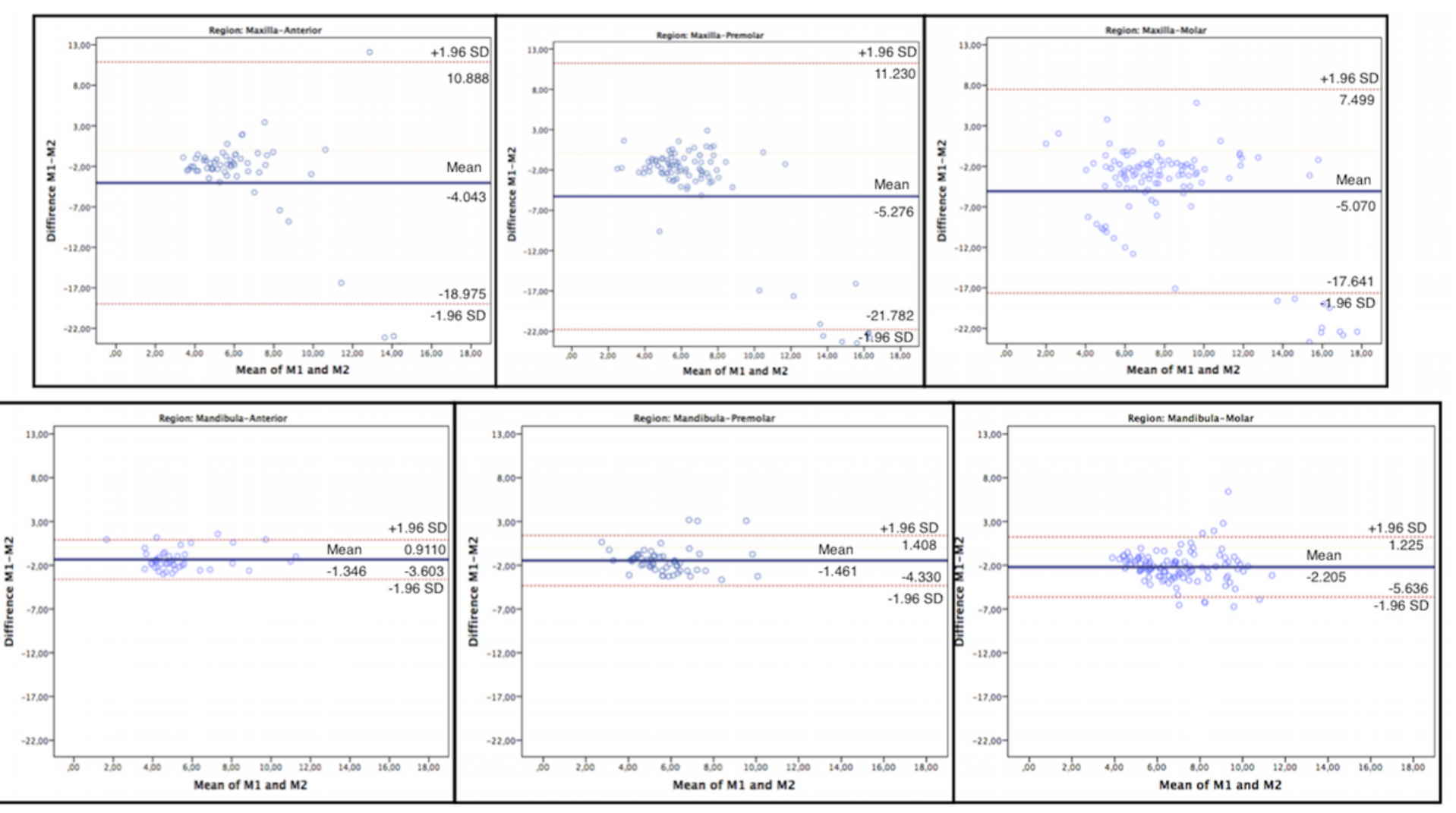

Figure 3

Bland Altman plots for bone thickness. M1, Manuel measurements; M2, Al measurements. 